\title{
AC 2008-147: APPLYING SIX SIGMA METHODOLOGY TO THE ADMISSIONS PROCESS IN HIGHER EDUCATION
}

\section{Alok Verma, Old Dominion University}

Dr. Alok K. Verma is Ray Ferrari Professor and, Director of the Lean Institute at Old Dominion University. He also serves as the Director of the Automated Manufacturing Laboratory and MET Program Director. Alok received his B.S. in Aeronautical Engineering from IIT Kanpur, MS in Engineering Mechanics and PhD in Mechanical Engineering from ODU. Prof. Verma is a licensed professional engineer in the state of Virginia, a certified manufacturing engineer and has certifications in Lean Manufacturing and Six Sigma. He has organized several international conferences as General Chair, including ICAM-2006 and ICAM-1999 and also serves as associate editor for three International Journals. His scholarly publications include 26 journal papers and 46 papers in conference proceedings. Dr. Verma has developed and delivered training program in Lean Enterprise \& Design for Manufacturing for Northrop Grumman Newport News, STIHL and several other companies in U.S. He has developed simulation based training programs for shipbuilding and repair industry under a grant from the National Shipbuilding Research Program (NSRP). He is well known internationally and has been invited to deliver keynote addresses at several national and international conferences on Lean/Agile manufacturing. Dr. Verma has received the Regional Alumni Award for Excellence for contribution to Lean Manufacturing research, the International Education Award at ODU and Ben Sparks Medal by ASME. He is active in ASME, ASEE, SME and SNAME. Dr. Verma continues to serve the Hampton Roads community in various leadership positions. 


\title{
Applying Six Sigma Methodology to the Admissions Process in Higher Education
}

\begin{abstract}
Time and quality are two important metrics for improving a company's production and profit performance. Six Sigma is one of the most powerful continuous improvement tools that have been used to improve the quality of products and business processes. Six Sigma methodology provides the techniques and tools to improve the capability and reduce the number of defects in any process. It was originally developed by Motorola to systematically improve processes by eliminating defects. Although, originally developed for manufacturing processes, the tool has been effectively applied to improve business processes also.

Evaluation of applications for admission in higher education is often a long and time consuming process. Long lead times and number of errors can be very frustrating for prospective students and their parents. This paper addresses the issues and concerns related to the admissions process at a University and makes recommendations for implementation. This study was completed as part of a master's project. The paper first outlines Six Sigma principle and then discusses various tools and techniques that can be applied to the admissions process. The delays in the application evaluation process are caused due to several factors, student not submitting credentials on time, delays at processing stations and delays due to un-necessary routing. A process map was created followed by data collection at various stations along the value stream. Finally DMAIC (Define, Measure, Analyze, Improve and Control) principles were applied to identify sources of bottlenecks and to suggest improvements to the process.
\end{abstract}

\section{Introduction}

Continuous improvement has been the power phrase for the last 15 years in the world of quality. Many definitions have been given and several philosophies have been developed to account for the introduction, development, implementation, and management of continuous improvement processes. Six-Sigma is a defined methodology and a set of statistical and quality tools used to improve the performance of a process so that the organization can realize financial benefits. Sigma (the lower-case Greek letter $\sigma$ ) is used to represent standard deviation of a population. The term "Six Sigma process" comes from the notion that if one has six standard deviations between the Mean of a process and the nearest specification limit, $99.999 \%$ of parts will meet design specifications. Sigma refers to the number of standard deviations between the process mean and the nearest specification limit, rather than the standard deviation of the process, which is also measured in "sigma". As process standard deviation goes up, or the mean of the process moves away from the center of the tolerance, the Process Capability sigma number goes down, because fewer standard deviations will then fit between the mean and the nearest specification limit. As sample size increases, the error in the estimate of standard deviation 
converges much more slowly than the estimate of the mean. It follows that estimates of defect rates can be very greatly influenced by uncertainty in the estimate of standard deviation.

Below figure shows the statistical way of representing data using Six Sigma. The +/- 6 standard deviations of the process are placed within the tolerance limits. The tolerance is defined as the difference between the Upper Statistical Limit (USL) and Lower Statistical Limit (LSL).

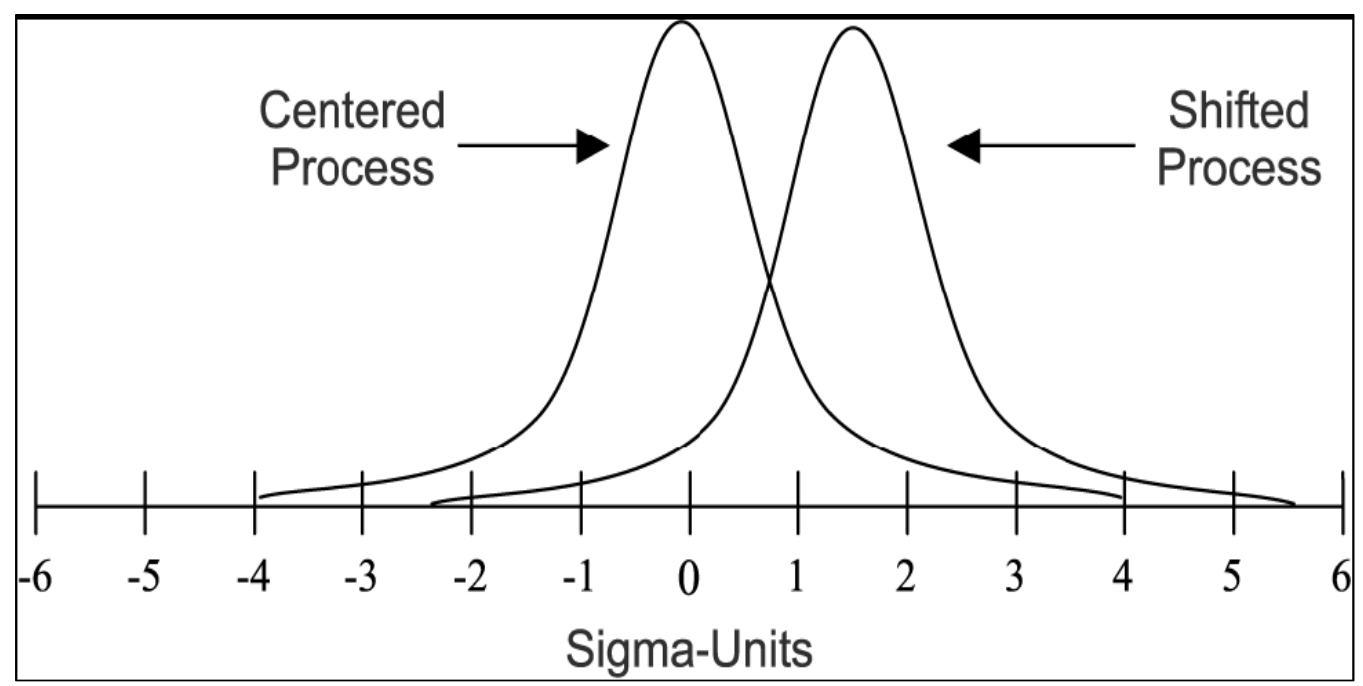

Figure 1: Graphical Analysis of Six Sigma

The goal is to reduce the variation of the process. There are no more than 3.4 defects per 1 million "units". Thus Six Sigma produces good "product" $99.999 \%$ of the time. Six-Sigma is a set of practices originally developed by Motorola to systematically improve processes by eliminating defects ${ }^{1}$. A defect is defined as nonconformity of a product or service to its specifications. While the particulars of the methodology were originally formulated by Bill Smith at Motorola in $1986^{2}$, Six Sigma was heavily inspired by six preceding decades of quality improvement methodologies such as Quality Control, TQM, and Zero Defects. Like its predecessors, Six Sigma asserts the following:

- Continuous efforts to reduce variation in process outputs is key to business success

- Manufacturing and business processes can be measured, analyzed, improved and controlled

- Succeeding at achieving sustained quality improvement requires commitment from the entire organization, particularly from top-level management

The admissions process which is the first step for any aspiring student creates a first impression about an institution. All academic institution bares the responsibility for creating a positive impression for students and parents and reducing the lead time for the application process.

Implementation of Six Sigma follows a five-step Define, Measure, Analyze, Improve, and Control (DMAIC) process. Each of these steps utilize multiple tools for data measurement 
analysis and control. In the following sections, we apply each of these steps to the admissions process.

\section{Define Phase}

The admissions process for undergraduate students at has been characterized by long lead times for application processing. This in turn has resulted in decrease in acceptance rate and selection of qualified applicants. The above is a result of a number of factors like tracking, communication, technology, staff, training, etc. Sometimes the delays are due to students not submitting the required transcripts on time, but most of the times other technical reasons are responsible for delay in processing the applications. Figure 2 shows a high level process map that was prepared to understand and define the problem.

\section{High Level Process Map}

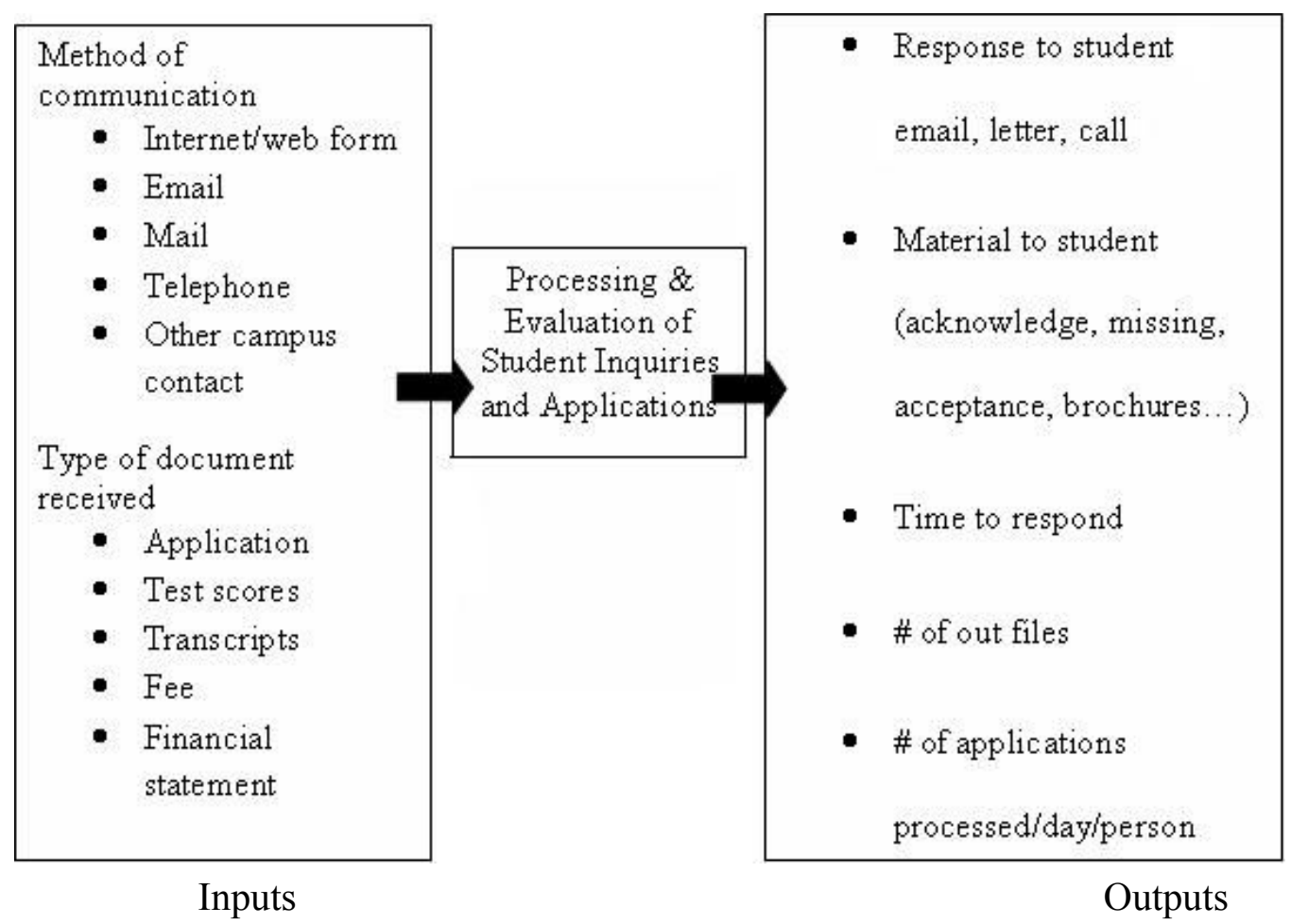

Figure 2: High Level Process Map

The process map identifies all the factors contributing to the application evaluation process.

\section{MEASURE PHASE}

This Phase identifies the measurement and variation by collecting the relevant data and performing graphical analysis on it $^{3}$. After identifying the factors in the Define previous phase, 
the admissions office was contacted for application processing data. Undergraduate applications were classified into three categories: Second Degree, Transfer and Freshman.

A 'sample size calculator' ${ }^{4}$ is used to determine the number of samples required under each category. Confidence level and confidence interval are two important terms needed for sample size calculation.

In statistics, a confidence interval (CI) is an interval estimate of a population parameter. Confidence intervals are used to indicate the reliability of an estimate. For example, a CI can be used to describe how reliable survey results are. All other things being equal, a survey result with a small $\mathrm{CI}$ is more reliable than a result with a large $\mathrm{CI}^{5}$.

The confidence level tells us how sure one can be. It is expressed as a percentage and represents how often the true percentage of the population who would pick an answer lies within the confidence interval. The $95 \%$ confidence level means one can be $95 \%$ certain; the $99 \%$ confidence level means one can be $99 \%$ certain. Most researchers use the $95 \%$ confidence level 5 .

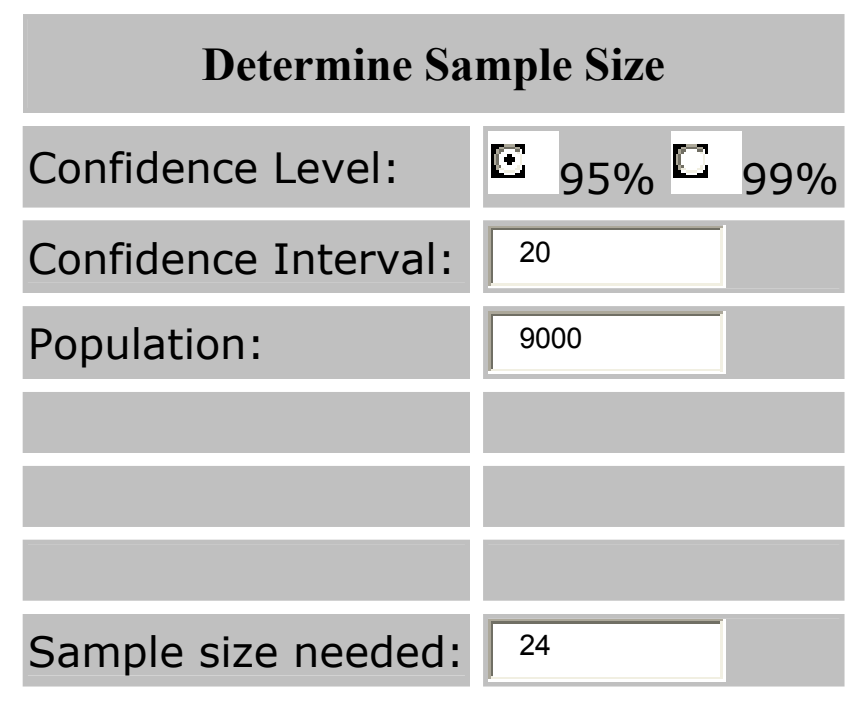

Figure 3: Sample Size Calculator

For a confidence level of $95 \%$ and a confidence interval of 20 , we got the sample size to be 24 for a population of 9000 using the sample size calculator. Hence, we collected twenty-five applications for each section. The data included -

- When the application came in

- When the transcripts came in

- When was the application declared to be complete with all required documents

- When was the evaluation done

- When was the decision made regarding the admission

- When was the decision letter printed and mailed 
The data was tabulated in Microsoft Excel to calculate the mean, standard deviation and to perform graphical analysis. For each of the three categories of applications, processing steps were identified along with the time required for processing in number of days.

\section{Second Degree Applications:}

Step 1: Application received - Transcripts received

Step 2: Transcripts received - Application complete

Step 3: Application complete - Sent for departmental review

Step 4: Sent for departmental review - Departmental chair approval

Step 5: Departmental Chair approval - College Dean approval

Step 6: College Dean approval - Sent back to Admissions office

Step 7: Admissions office - Admission granted

Step 8: Admission granted - Admission letter printed

The mean and standard deviation for the data collected is calculated to understand which steps are causing delays in the process.

\begin{tabular}{|l|r|r|r|r|r|r|r|r|r|r|r|r|r|r|r|r|r|r|r|r|r|r|r|r|r|r|r|}
\hline \multicolumn{110}{|c|}{} & Second Degree Applications \\
\hline & $\mathbf{1}$ & $\mathbf{2}$ & $\mathbf{3}$ & $\mathbf{4}$ & $\mathbf{5}$ & $\mathbf{6}$ & $\mathbf{7}$ & $\mathbf{8}$ & $\mathbf{9}$ & $\mathbf{1 0}$ & $\mathbf{1 1}$ & $\mathbf{1 2}$ & $\mathbf{1 3}$ & $\mathbf{1 4}$ & $\mathbf{1 5}$ & $\mathbf{1 6}$ & $\mathbf{1 7}$ & $\mathbf{1 8}$ & $\mathbf{1 9}$ & $\mathbf{2 0}$ & $\mathbf{2 1}$ & $\mathbf{2 2}$ & $\mathbf{2 3}$ & $\mathbf{2 4}$ & $\mathbf{2 5}$ & Mean & Std. Deriation \\
\hline Step 1 & 2 & 1 & 27 & 57 & 5 & 27 & 9 & 75 & 8 & 3 & 0 & 16 & 5 & 2 & 1 & 7 & 7 & 13 & 12 & 0 & 7 & 0 & 28 & 0 & 2 & 12.56 & 18.00684314 \\
\hline Step 2 & 1 & 0 & 0 & 1 & 27 & 0 & 1 & 8 & 2 & 4 & 8 & 0 & 17 & 0 & 1 & 14 & 2 & 6 & 0 & 4 & 4 & 21 & 0 & 0 & 0 & 4.84 & 7.192662928 \\
\hline Step 3 & 0 & 0 & 6 & 0 & 1 & 2 & 113 & 1 & 7 & 4 & 2 & 1 & 1 & 0 & 0 & 20 & 4 & 3 & 0 & 3 & 5 & 14 & 1 & 0 & 10 & 7.92 & 21.97256471 \\
\hline Step 4 & 3 & 5 & 27 & 37 & 4 & 27 & 26 & 9 & 8 & 4 & 3 & 12 & 12 & 12 & 4 & 7 & 25 & 29 & 9 & 13 & 8 & 61 & 6 & 29 & 21 & 16.04 & 13.57491805 \\
\hline Step 5 & 2 & 3 & 7 & 0 & 5 & 119 & 0 & 4 & 1 & 7 & 3 & 0 & 1 & 0 & 2 & 2 & 9 & 0 & 3 & 7 & 1 & 4 & 2 & 2 & 3 & 7.48 & 22.89649755 \\
\hline Step 6 & 1 & 3 & 3 & 4 & 6 & 6 & 2 & 6 & 4 & 0 & 12 & 3 & 12 & 2 & 1 & 4 & 2 & 0 & 2 & 1 & 4 & 4 & 2 & 1 & 3 & 3.52 & 3.008255308 \\
\hline Step 7 & 1 & 1 & 7 & 1 & 1 & 8 & 1 & 2 & 1 & 1 & 94 & 3 & 6 & 0 & 1 & 0 & 5 & 0 & 0 & 3 & 1 & 2 & 56 & 1 & 1 & 7.88 & 20.62099901 \\
\hline Step 8 & 4 & 2 & 1 & 3 & 6 & 6 & 11 & 9 & 2 & 4 & 0 & 4 & 4 & 2 & 34 & 2 & 3 & 1 & 2 & 4 & 2 & 4 & 0 & 9 & 3 & 4.88 & 6.525764323 \\
\hline
\end{tabular}

Table 1: Data for Second Degree Applications

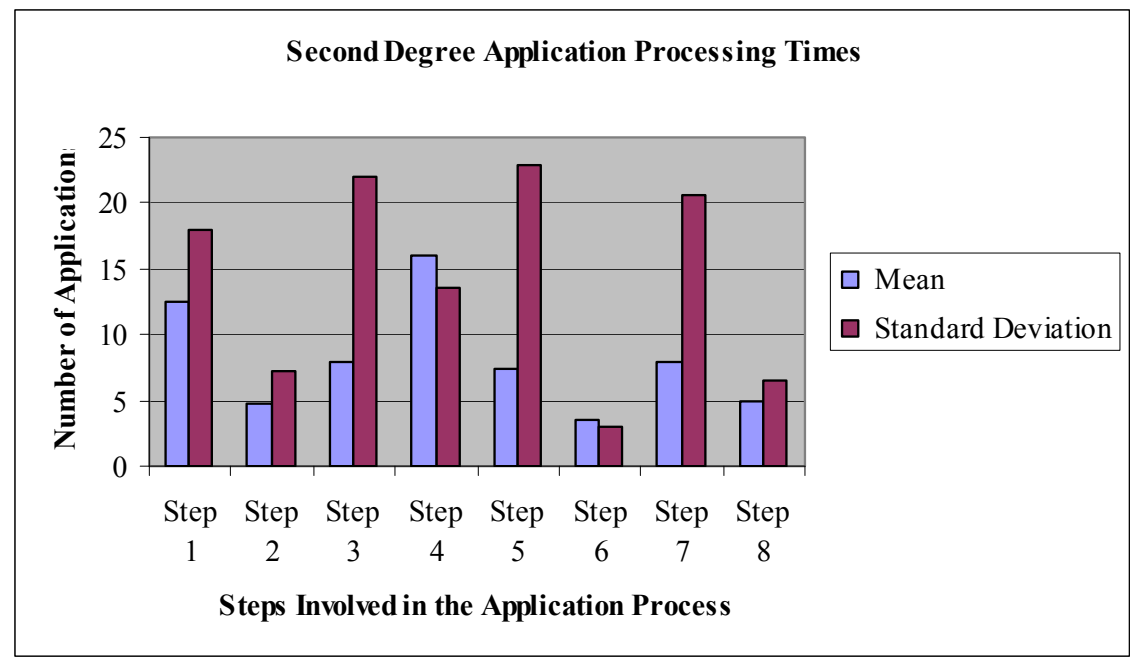

Figure 4: Graphical Representation of Mean and Standard Deviation for Second Degree Applications 
Steps with longer processing time certainly need attention however, processes with higher standard deviation may also warrant attention since the larger variation in processing times may be result of an unstable process. From the graph above and the data collected, steps1, $2,3,5,7$ and 8 have longer processing times. Thus, we need to focus on these steps.

\section{Transfer Applications:}

The following steps are involved in the processing of transfer applications.

Step 1: Application received - Transcripts received

Step 2: Transcripts received - Application complete

Step 3: Application complete - Evaluation done

Step 4: Evaluation done - Admission granted

Step 5: Admission granted - Admission letter printed

Bringing together these steps and the relevant data for interpretation in Microsoft excel sheet gives the following result.

\begin{tabular}{|c|c|c|c|c|c|c|c|c|c|c|c|c|c|c|c|c|c|c|c|c|c|c|c|c|c|c|c|c|}
\hline \multicolumn{29}{|c|}{ Transfer Applications } \\
\hline & 1 & T & & & & 5 & 6 & 7 & 8 & & 10 & 11 & 12 & 13 & 14 & 15 & 16 & 17 & 18 & 19 & 20 & 21 & 22 & 23 & 24 & & Mean & Std. Deriation \\
\hline Step I & 29 & 11 & & & 4 & 9 & 5 & 36 & 36 & 35 & 83 & 1 & 45 & 8 & 83 & 27 & 15 & 1 & 16 & 17 & 8 & 24 & 54 & 2 & 5 & 1 & 22.24 & 23.229774 \\
\hline Step 2 & 5 & 76 & 1 & & 4. & if & 11 & 4 & 3 & 3 & 3 & 14 & 5 & 5 & 1 & 1 & 4 & 3 & 3 & 92 & 6 & 2 & 10 & 0 & 5 & 9 & 12.8 & \begin{tabular}{|l|l|} 
& 21.76786623 \\
\end{tabular} \\
\hline Step 3 & 11 & 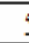 & & 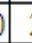 & & 0 & 2 & 9 & 4 & 4 & 19 & 12 & 12 & 16 & 66 & 0 & 14 & 19 & 5 & 10 & 0 & 7 & 21 & 34 & 6 & 11 & 12.32 & \begin{tabular}{|l|l}
13.64615697 \\
\end{tabular} \\
\hline Step 4 & 0 & 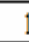 & & & 0 & 2 & 3 & 0 & 1 & 0 & 30 & 14 & 0 & 0 & 0 & 1 & 0 & 0 & 7 & 11 & 9 & 7 & 1 & 8 & 14 & 0 & 4.4 & 6.899275324 \\
\hline Step 5 & 7 & 8 & & t) & 3 & 1 & 9 & & 17 & 3 & 1 & 2 & 8 & 9 & 0 & 9 & 2 & 0 & 3 & 2 & 11 & 3 & 14 & 2 & 6 & 3 & 5.4 & 4.5607017 \\
\hline
\end{tabular}

Table 2: Data for Transfer Applications

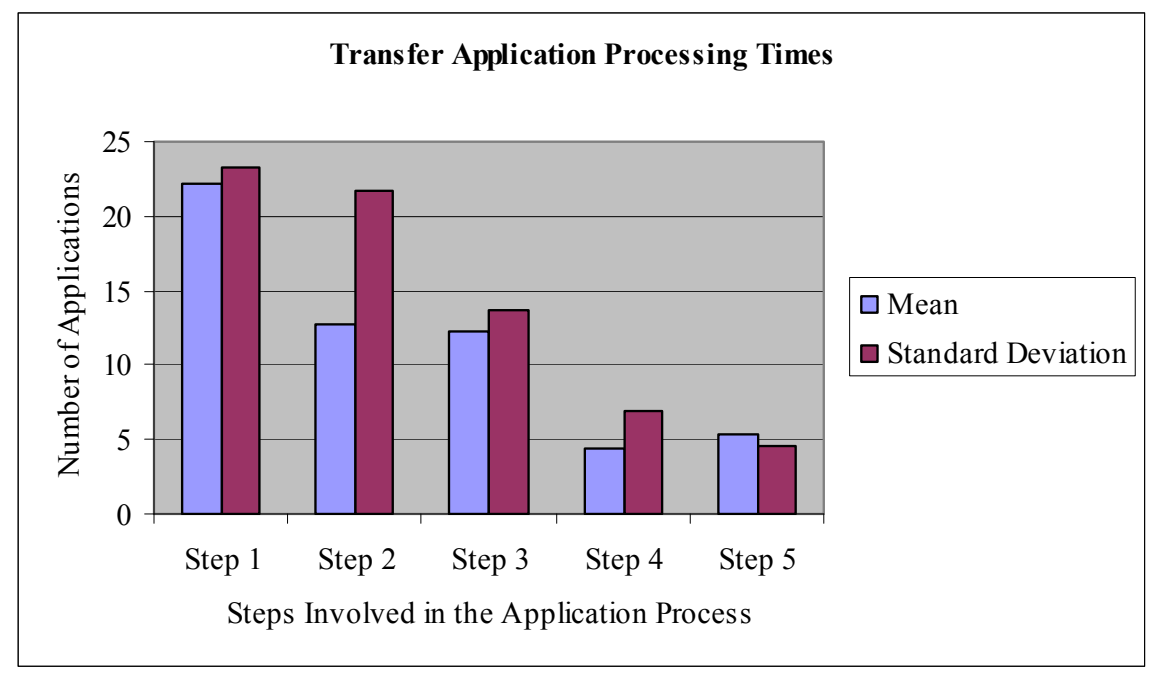

Figure 5: Graphical Representation of Mean and Standard Deviation for Transfer Applications 
From the above graph, looking at the mean and standard deviation, we need to focus on steps 1, 2, 3 and 4 .

\section{Freshman Applications:}

Step 1: Application received - Transcripts received

Step 2: Transcripts received - Recommendations received

Step 3: Recommendations received - Application complete

Step 4: Application complete - Evaluation done

Step 5: Evaluation done - Admission granted

Step 6: Admission granted - Admission letter printed

\begin{tabular}{|c|c|c|c|c|c|c|c|c|c|c|c|c|c|c|c|c|c|c|c|c|c|c|c|c|c|c|c|}
\hline \multicolumn{28}{|c|}{ Freshman Applications } \\
\hline & 1 & 2 & 3 & 4 & 5 & 6 & 7 & 8 & & 10 & 11 & \begin{tabular}{l|l}
12 & 13 \\
\end{tabular} & \begin{tabular}{|l|l|}
3 & 14 \\
\end{tabular} & 15 & 16 & & 18 & $\mathrm{l}$ & & 02 & $\begin{array}{l}12 \\
2\end{array}$ & 2 & 23 & 24 & & Mean & Std. Deriation \\
\hline Step 1 & 3 & 9 & 14 & 4 & & 9 & 64 & 88 & 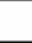 & 28 & 1 & \begin{tabular}{l|l}
162 \\
16
\end{tabular} & \begin{tabular}{|l|l|}
25 \\
\end{tabular} & 0 & 3 & 22 & 23 & 2 & 2 & 21 & \begin{tabular}{l|l}
6 & 3 \\
6
\end{tabular} & 33 & 21 & 4 & 1 & 15.36 & 20.21460558 \\
\hline Step 2 & 0 & 0 & 0 & 5 & & 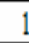 & 0 & 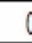 & 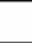 & 0 & 0 & 0.4 & \begin{tabular}{|l|l|}
4 & 39 \\
\end{tabular} & 3 & 0 & 7 & 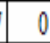 & & & 1 & 0 & 0 & 0 & 0 & 0 & 2.76 & 7.659138333 \\
\hline Step 3 & 6 & 10 & 34 & 2 & 2 & 1 & 4 & 7 & 7 & 29 & 12 & \begin{tabular}{l|l}
6 & 3 \\
\end{tabular} & \begin{tabular}{l|l|}
3 & 1 \\
\end{tabular} & 5 & 11 & 10 & trat & 1. & & \begin{tabular}{l|l}
43 \\
\end{tabular} & & 4 & 2 & 7 & 3 & 11.28 & 15.6320696 \\
\hline Step 4 & 0 & 2 & 4 & 0 & 0 & 0 & 2 & g & 3 & 40 & 0 & \begin{tabular}{l|l}
2 & 3 \\
\end{tabular} & \begin{tabular}{l|l}
3 & 2 \\
\end{tabular} & 21 & 55 & 3 & 8 & 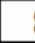 & & 2 & 1 & 14 & & 30 & 1 & 7.28 & 12.99082753 \\
\hline Step 5 & 0 & 0 & 0 & 0 & 0 & 0 & 0 & 1 & 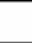 & 2 & 0 & 1.1 & $\begin{array}{ll}1 & 0 \\
1\end{array}$ & 0 & 9 & 0 & 0 & & & 0 & 0 & 0 & 0 & 0 & I & 0.6 & 1.788854382 \\
\hline Step 6 & 3 & 2 & 4 & 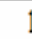 & 2 & . & 8 & & & \begin{tabular}{l|l}
1 & 1 \\
\end{tabular} & 3 & 117 & $\begin{array}{ll}7 & 1 \\
\end{array}$ & 3 & 8 & 4 & 0 & & & 2 & 2 & 0 & 1 & 1 & 3 & 2.4 & 2.244994432 \\
\hline
\end{tabular}

Table 3: Data for Freshman Applications

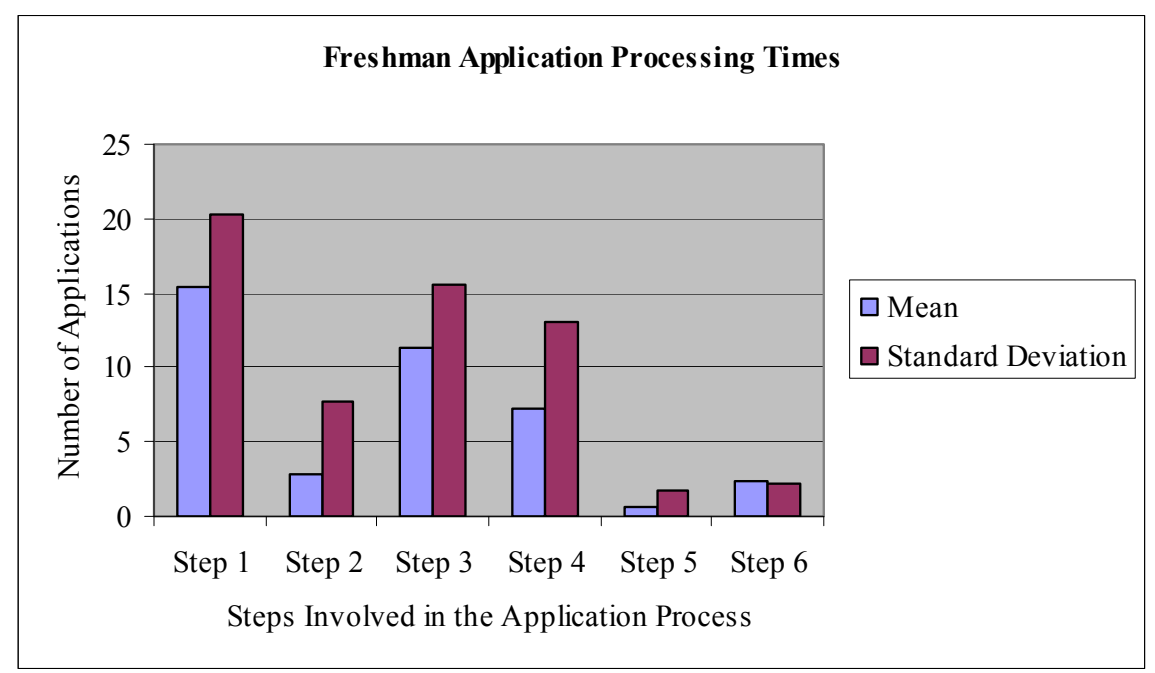

Figure 6: Graphical Representation of Mean and Standard Deviation for Freshman Applications

For the freshman applications, steps 1, 2, 3 and 4 have the largest mean and standard deviation and are the main reasons for delay in the freshman applications.

\section{Office Layout:}

The office layout for all the three categories (second degree, transfer, freshman applications) were drawn to evaluate the travel time and distance for documents from one step to 
other. Complicated room layout can make the application staff tired, frustrated, confused leading to delays.

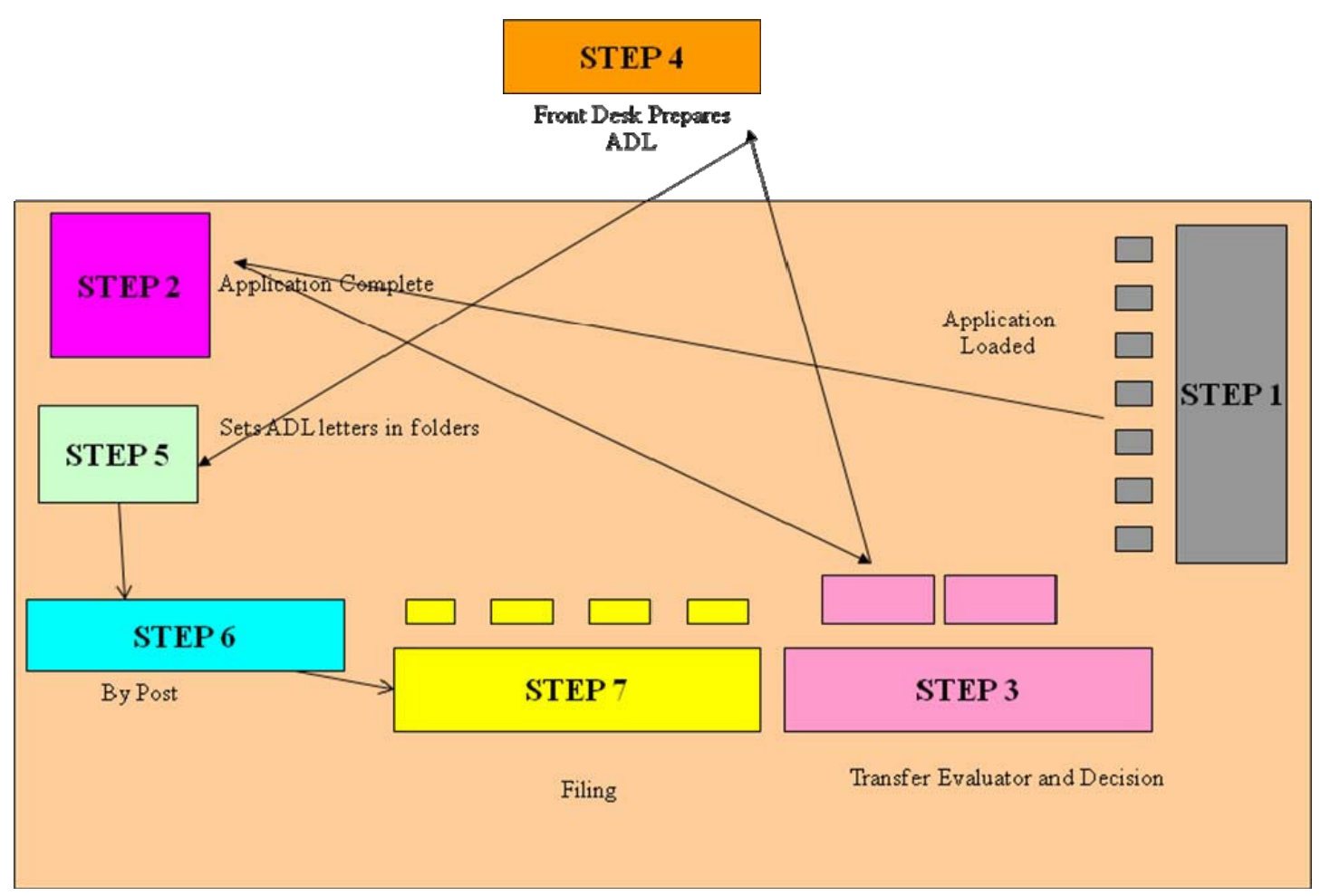

Figure 7: Office Layout for Freshman/Transfer Applications Before

Figure 7 shows the room layout for freshman/transfer applications. The applications are initially loaded into the computer by the coordinators, and then the applications are transferred to another station for completion check. At step 3, the transfer evaluators make the decision for admission. The front desk prepares the Admission letters. These letters are placed in the folders for future reference and a copy of this letter is mailed to the student.

A similar procedure is followed for the second-degree applications. The only difference is that these are sent to the respective departments to make decision on admission. Below is the room layout for second-degree application process.

\section{Analyze Phase}

At this stage of Six Sigma implementation, we have narrowed our focus on a distinct group of processes that may be responsible for delays. During the analyze phase, we try to identify the reasons for delay in these processes. Fish Bone Diagram also known as Cause and Effect Diagram or Ishikawa diagram is used to analyze reasons behind the problem causing areas. 


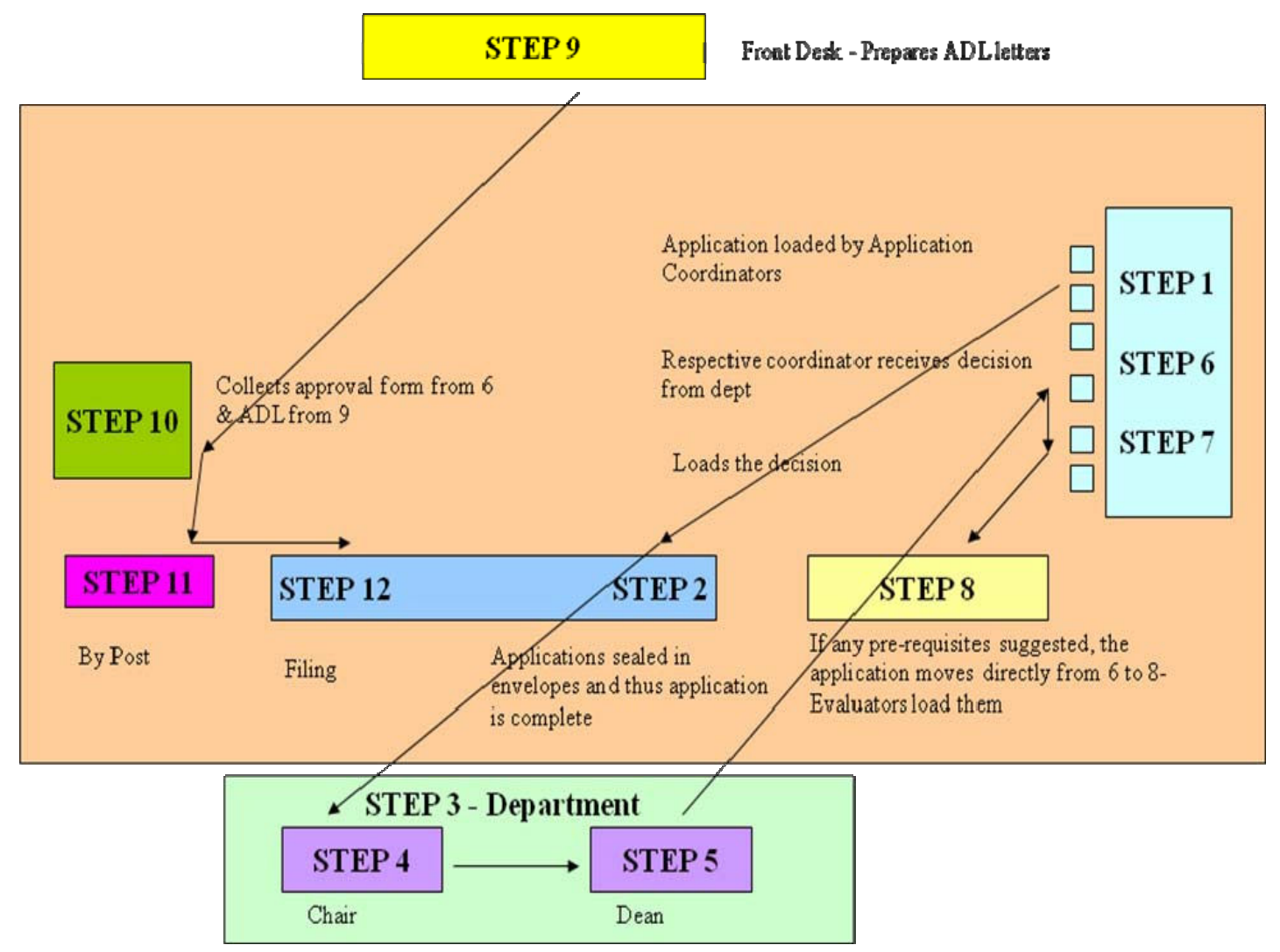

Figure 8: Office Layout for Second Degree Applications Before

\section{Cause and Effect Diagram / Fish Bone Diagram}

The cause and effect diagram is used to explore all the potential or real causes (or inputs) that result in a single effect (or output) ${ }^{7}$. Causes are arranged to their level of importance or detail, resulting in a depiction of relationships and hierarchy of events. Thus helps in the search for root causes, identify areas where there may be problems, and compare the relative importance of different causes ${ }^{8}$. The cause and effect diagram is also known as fish bone diagram because it was drawn to resemble the skeleton of a fish, with the main causal categories drawn as 'bones' attached to the spine of the fish. The fishbone diagram is also helpful in displaying the many potential causes for a specific problem leading to a more robust solution.

\section{Recommendations}

After performing the analysis using fishbone diagram and looking at the above mentioned causes for the delay in the admissions process we came up with the following recommendations.

- Triage process ${ }^{11}$-The staff should be aware of notifying the appropriate parties when a situation arises, making sure the situation is handled properly, fixed and documented for future purposes.

- Communication - The students should be sent reminders periodically every week regarding their status of their application to their emails along with placing it online. 
- Improvement/ Implementation/ Accountability - Staff should take accountability for any delays in processing, communication, etc and work on improving the process. Training for staff and supervisors in six sigma methodology is recommended.

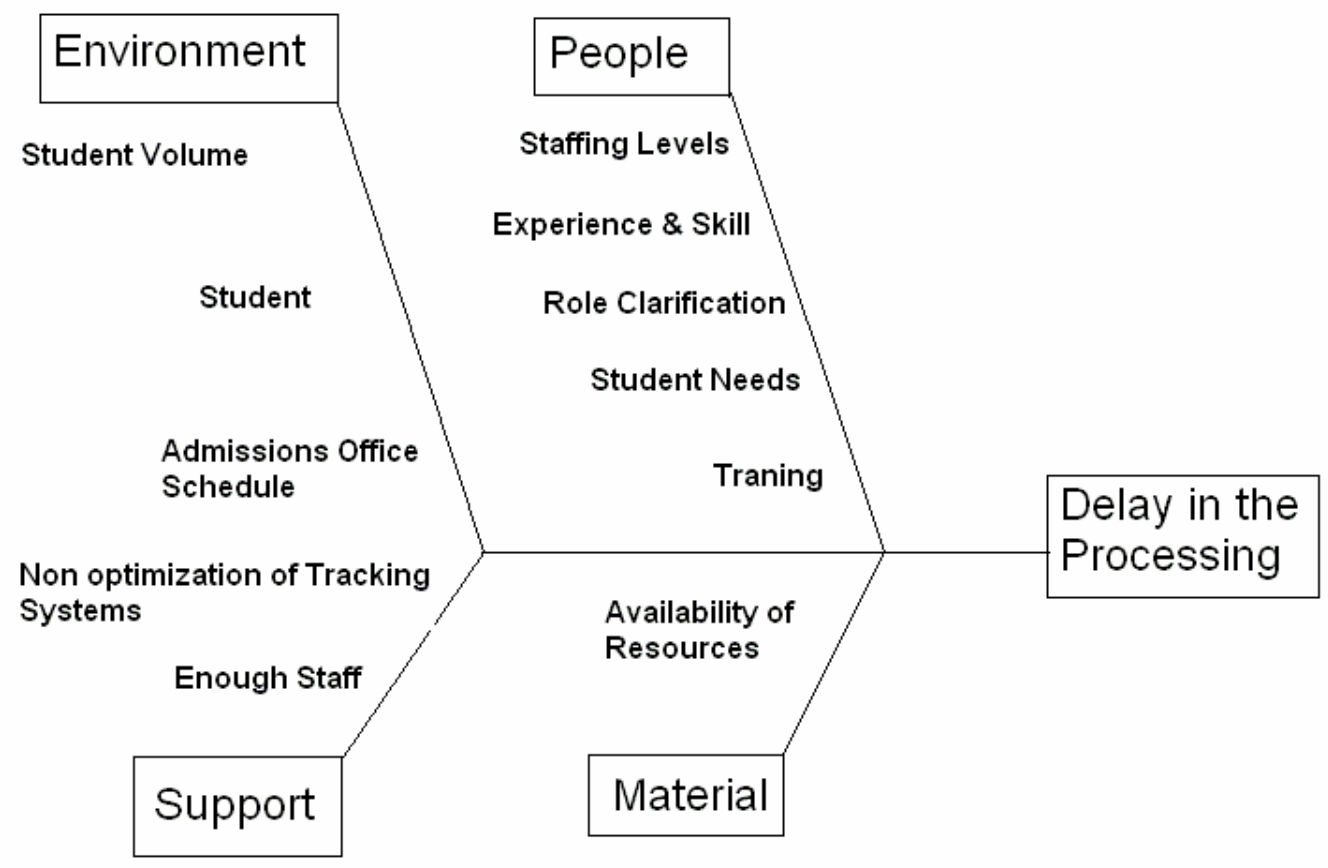

Figure 9: Fishbone Analysis of the Project

- Feedback systems to quality auditing - Conduct a survey on student satisfaction in the application processing, then based on the numbers come up with plans to sustain or improve. This shall fill up the gap between the staff and the students, thus proves to be an effective tool.

- Need for improved flow sheet format - Come up with a template for the process so that everyone is on board with the process and make changes/updates regularly based on demands. By doing so everyone would be aware of the happenings within the process, no one remains in the dark. Also staff members tries to keep their work updated and up to the mark.

- One-on-one meetings - This is a meeting of the staff members with their immediate supervisors. In this meeting the supervisor and the staff member shares their opinion on each others work and clarifies their expectations from each other. This not only helps to solve their problems and concentrate on work but also helps to build healthy relationship and hence a healthy atmosphere to work.

- Peak period - During peak times i.e., when the volume of the number of applications coming in increases, then instead of overloading the staff it would be good to bring outside people, train them and get the work done. 
- File management guidelines - Make the work load visual. Place in and out boxes (red and green) on each work station. When a file moves from one station to another, the file is placed in the red box.

- Out cards - The staff members should check the number of applications coming in and going out of the office. Take immediate or timely action on the file which has been out of office longer than a specified time.

- Workspace redesigned - Space coordinated according to the work processes. Better desk space and file co-ordination.

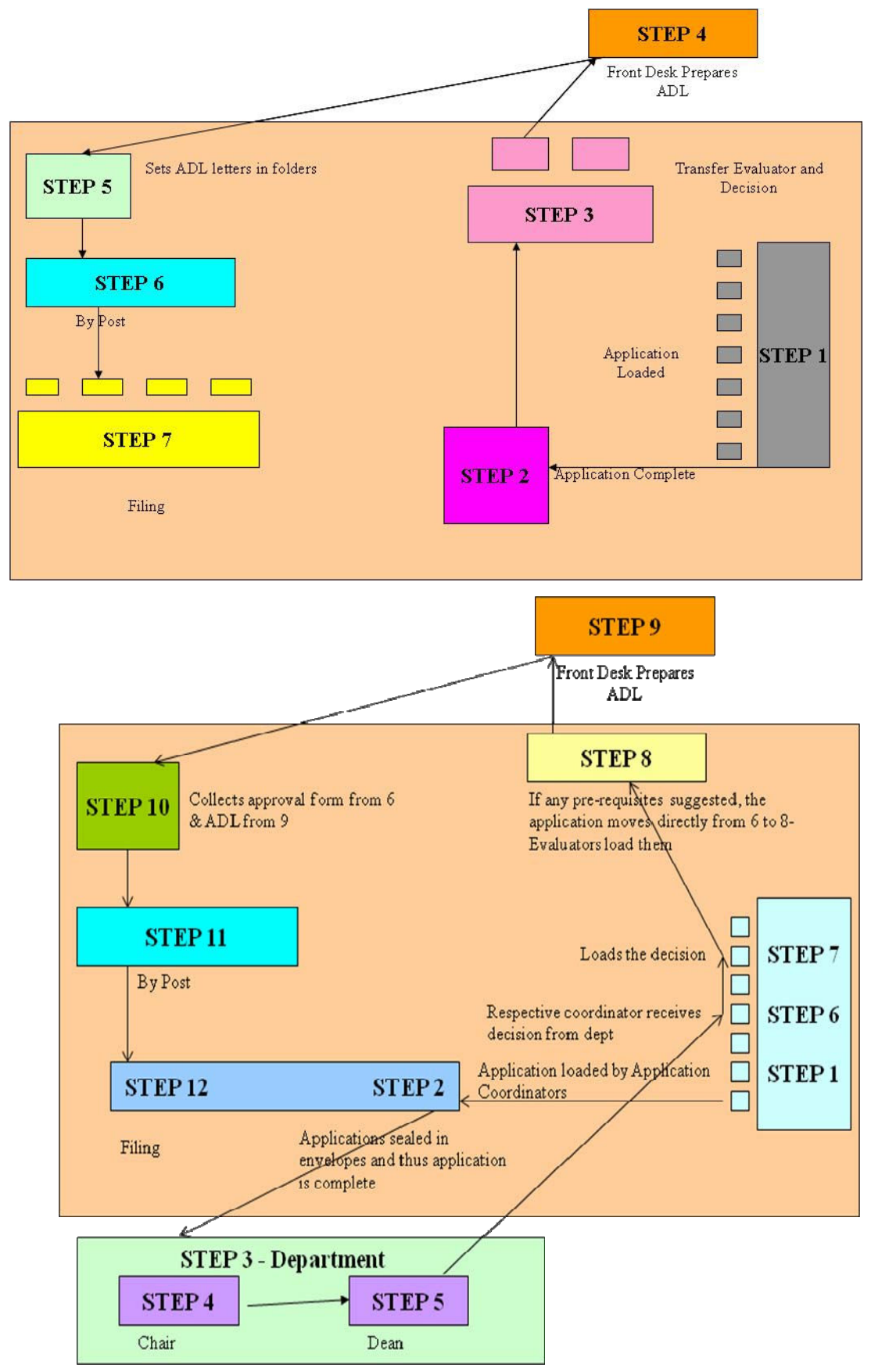

Figure 10: Redesigned Office Layout for Second Degree Applications 


\section{Conclusions}

Six-Sigma methodology has been applied to the admissions process at a higher education institution. The methodology offers a detailed step by step implementation process for improving a process. Data collected on processing times were used to identify key steps resulting in delay. During the analysis phase, key reasons behind the delay were identified. The recommendation made as a result of this study can lead to the following benefits:

- Increased satisfaction with inquiries and applicants.

- Increased enrollment yield of students that apply.

- Improved perception, integrity, and accountability of office.

- Simpler and better defined process for university employees and students.

- More student-friendly customer service.

- Improved employee satisfaction resulting in fewer turnovers.

- Quicker and more accurate view of status of applications.

\section{References}

1. "Six Sigma: What It Is and How to Use It." Harvard Management Update June 1999, pp. 6- 7.

2. Breyfogle W.F., M.J. Cupello, and B. Meadows. Managing Six Sigma: A Practical Guide to Understanding, Assessing and Implementing the Strategy that Yields Bottom Line Success. Hoboken, NJ: John Wiley \& Sons, 2001. ISBN 0-471-39673-7.

3. Hahn J.G., N. Doganaksoy, and R. Hoerl. "The Evolution of Six Sigma." Quality Engineering Journal, vol. 12 , no. 3, 2000, pp. 317-326.

4. http://www.surveysystem.com/sscalc.htm

5. Fisher, R.A. (1956), Statistical Methods and Scientific Inference, Oliver and Boyd, Edinburgh, pp. 32.

6. Freund, J.E. (1962), Mathematical Statistics Prentice Hall, Englewood Cliffs, NJ, pp. 227-228.

7. Sanders D., and C. Hild, “A Discussion of Strategies for Six Sigma Implementation.” Quality Engineering Journal. Vol. 12, no. 3, pp. 311- 315.

8. Scherkenbach, William W. (1998), The Deming Route to Quality and Productivity: Road Maps and Roadblocks, ASQC Quality Press, Milwaukee, WI.

9. Harry, Mikel J. (January 2000b), A New Definition Aims to Connect Quality Performance with Financial Performance, Quality Progress 33(1): 64- 66.

10. Snee, Ronald D. (September 1999a), Why Should Statisticians Pay Attention to Six Sigma? An Examination for Their Role in the Six Sigma Methodology, Quality Progress 32(9): 100- 103.

11. Kaplan, Robert S., and David P. Norton. The Balanced Scorecard. Boston: Harvard Business School Press, 1996.

12. Blakeslee, J.A. "Implementing the Six Sigma Solution." Quality Progress, vol. 32, no. 7, July 1999, pp. 7785. 